\title{
Four emerging arboviral diseases in North America: Jamestown Canyon, Powassan, chikungunya, and Zika virus diseases
}

\author{
Daniel M. Pastula ${ }^{1}$ - Daniel E. Smith ${ }^{1}$ - J. David Beckham ${ }^{1} \cdot$ Kenneth L. Tyler $^{1}$
}

Received: 11 January 2016 / Accepted: 9 February 2016 / Published online: 22 February 2016

(C) Journal of NeuroVirology, Inc. 2016

\begin{abstract}
Arthropod-borne viruses, or arboviruses, are viruses that are transmitted through the bites of mosquitoes, ticks, or sandflies. There are numerous arboviruses throughout the world capable of causing human disease spanning different viral families and genera. Recently, Jamestown Canyon, Powassan, chikungunya, and Zika viruses have emerged as increasingly important arboviruses that can cause human disease in North America. Unfortunately, there are currently no proven disease-modifying therapies for these arboviral diseases, so treatment is largely supportive. Given there are also no commercially available vaccines for these four arboviral infections, prevention is the key. To prevent mosquito or tick bites that might result in one of these arboviral diseases, people should wear long-sleeved shirts and pants while outside if feasible, apply insect repellant when going outdoors, using window screens or air conditioning to keep mosquitoes outside, and perform tick checks after being in wooded or brushy outdoor areas.
\end{abstract}

Keywords Arbovirus $\cdot$ Arboviral disease $\cdot$ Jamestown Canyon virus $\cdot$ Powassan virus $\cdot$ Chikungunya virus $\cdot$ Zika virus $\cdot$ North America

Arthropod-borne viruses, or arboviruses, are viruses that are transmitted through the bites of mosquitoes, ticks, or sandflies.

Daniel M. Pastula

Daniel.Pastula@ucdenver.edu

1 Neuro-Infectious Diseases Group, Department of Neurology and Division of Infectious Diseases, University of Colorado Denver, 12401 East 17th Avenue, Mailstop L950, Room 486,

Aurora, CO 80045, USA
There are numerous arboviruses throughout the world spanning different viral families and genera capable of causing human disease (CDC Arbocat website). West Nile and dengue virus diseases are probably the most well known arboviral diseases in North America, with St. Louis encephalitis, La Crosse, and eastern equine encephalitis virus diseases also being familiar to many clinicians. Recently, Jamestown Canyon, Powassan, chikungunya, and Zika viruses have emerged as increasingly important arboviruses that can cause human disease in North America.

Jamestown Canyon virus is an orthobunyavirus (family Bunyaviridae) first identified in Jamestown Canyon, Colorado, in 1961 (CDC Arbocat website). It is thought to be mosquito-borne and has been recovered in various Aedes, Coquillettidia, Culex, and Culiseta mosquito species (Anderson et al. 2015; Andreadis et al. 2008). The exact geographic range of Jamestown Canyon virus is unclear; however, neutralizing antibody results from animals and humans suggest it is widespread throughout North America (Aguirre et al. 1992; Grimstad et al. 1986; Walters et al. 1999). A recent analysis of 31 confirmed Jamestown Canyon virus infections in the USA from 2000 to 2013 showed cases occurred across 13 states, including some western, midwestern, northeastern, and southern states (Pastula et al. 2015). Jamestown Canyon virus infections mostly occur from spring to early fall, affect all age groups, and appear to have a slight male predominance (Pastula et al. 2015). Clinically, Jamestown Canyon virus infections may present as a nonspecific febrile illness, meningitis, or meningoencephalitis (Deibel et al. 1983; Pastula et al. 2015). The percentage of asymptomatic Jamestown Canyon virus infections is unknown. Approximately half of reported infections result in hospitalization, but no deaths have been reported to date (Pastula et al. 2015). Differentiating between Jamestown Canyon and La Crosse virus (another orthobunyavirus) infection is challenging as there is partial 
cross-reactivity of Jamestown Canyon virus immunoglobulin (Ig) $\mathrm{M}$ antibodies using the La Crosse virus IgM enzymelinked immunosorbent assay (ELISA) test (Pastula et al. 2015). Plaque reduction neutralization tests (PRNTs) or possibly reverse transcription-polymerase chain reaction (RT-PCR) performed on serum and/or cerebrospinal fluid (CSF) may help confirm the diagnosis of Jamestown Canyon virus infection, but only a few public health laboratories in North America are currently able to perform them. Interestingly, Jamestown Canyon virus disease may be historically under-recognized given the marked increase in confirmed Jamestown Canyon virus infections in the USA in 2013, the first year the U.S. Centers for Disease Control and Prevention (CDC) implemented routine Jamestown Canyon IgM antibody screening of domestic samples (Pastula et al. 2015).

Powassan virus is a flavivirus (family Flaviviridae) first identified in Powassan, Ontario, in 1958 (CDC Arbocat website). Powassan virus is transmitted by ticks, specifically Ixodes cookei, marxi, and scapularis species (CDC Powassan virus website). There are two lineages of Powassan virus, lineage 1 and lineage 2 (also known as deer tick virus), and both are capable of causing human disease. From 2004 to 2013, 57 cases of Powassan virus disease were reported to the $\mathrm{CDC}$, mostly in residents of the Great Lakes and Northeast regions of the USA (CDC Powassan virus website). Powassan virus disease has also been reported in Canada and even far eastern Russia (Ebel 2010). Powassan virus infections usually occur from late spring through fall, when ticks are most active, and have been reported across all age groups in both sexes (CDC Powassan virus website; Hinten et al. 2008; Johnson et al. 2010). Clinically, infection with Powassan virus is usually asymptomatic, but can lead to a severe meningoencephalitis, which is fatal in approximately $10 \%$ of cases (CDC Powassan virus website; Hinten et al. 2008; Johnson et al. 2010). Diagnosis of Powassan virus is largely serologic, as Powassan virus or Powassan virus nucleic acid is often difficult to isolate in clinical samples (CDC Powassan virus website). A positive Powassan virus IgM ELISA test followed by confirmatory PRNTs on the serum and/or CSF may help confirm Powassan virus infection, but only a few public health laboratories in North America are currently able to perform them. Similar to Jamestown Canyon virus disease, reported Powassan virus disease cases have increased in the past few years, possibly due to increased recognition and reporting and/or a true increased number of cases (CDC Powassan virus website; Johnson et al. 2010).

Chikungunya virus is an alphavirus (family Togaviridae) first identified in Tanzania in 1953 (CDC Arbocat website). Chikungunya virus is transmitted by Aedes species of mosquitoes, typically Aedes aegypti and Aedes albopictus (CDC chikungunya virus website). During outbreaks, chikungunya virus is transmitted from humans to mosquitoes to humans, similar to the dengue viruses (Staples et al. 2009). Prior to
2013, chikungunya virus disease outbreaks had been reported in Africa, islands in the Indian Ocean, India, and Southeast Asia (Staples et al. 2009; Thiberville et al. 2013). There was even a brief chikungunya virus disease outbreak in Italy in 2007 with human-mosquito-human transmission thought to be due to an infected traveler importing the virus (Angelini et al. 2007). In late 2013, local chikungunya virus transmission was reported for the first time in the Western Hemisphere on the Caribbean island of Saint Martin, again possibly imported by an infected traveler (Fischer and Staples 2014). From 2013 to 2015 , chikungunya virus rapidly spread throughout 45 countries in tropical and subtropical North and South America with over 1.7 million suspected chikungunya virus disease cases reported (CDC chikungunya virus website). In the USA, local transmission has been documented in Florida, Puerto Rico, and the US Virgin Islands. Similar to the dengue viruses, chikungunya virus infections can occur at any time of year in tropical and subtropical areas, so long as certain Aedes species of mosquitoes are present and active. Chikungunya virus affects all age groups in both sexes. Clinically, infection with chikungunya virus is usually symptomatic, often causing a febrile illness with severe polyarthralgia (hence, the name "chikungunya," meaning "that which bends" in the Makonde language of Tanzania). Deaths are rare, occurring in $<1 \%$ of cases. Morbidity, however, can be significant as some have persistent polyarthralgias (Staples et al. 2009; CDC chikungunya virus website). Neurologic complications are not common, but there are reports of chikungunya virus infection associated with meningoencephalitis, myelitis, and Guillain-Barré syndrome (CDC chikungunya virus website; Geradin et al. 2016; Lebrun et al. 2009; Oehler et al. 2015). Diagnosis of chikungunya virus can be made either serologically by chikungunya virus IgM antibody tests or molecularly through detection of viral nucleic acid by RT-PCR. These tests are available at a few commercial laboratories and at several public health laboratories (CDC chikungunya virus website).

Zika virus is another flavivirus (family Flaviviridae) first identified in the Zika Forest of Uganda in 1947 that is now rapidly spreading throughout parts of the Americas (CDC Arbocat website). Similar to the dengue viruses and chikungunya virus, Zika virus is also transmitted by certain Aedes species of mosquitoes and propagates from humans to mosquitoes to humans during outbreaks (CDC Zika virus website). Until 2007, there were only 14 Zika virus disease cases documented until an outbreak occurred in Yap State in the Federated States of Micronesia (Duffy et al. 2009). In late 2013, an outbreak of Zika virus disease began in French Polynesia, then spread to Easter Island in 2014 (Musso et al. 2014). In 2015, local transmission of Zika virus was confirmed in Brazil, with rapid spread throughout parts of South America thereafter. By January 2016, local transmission of Zika virus was also reported in Mexico, Central America, 
and in some islands of the Caribbean, including Puerto Rico and the U.S. Virgin Islands (CDC Zika virus website). No local transmission of Zika virus has been reported in the continental USA as of January 2016, but that many change in the future. Similar to the dengue viruses and chikungunya virus, Zika virus infections can occur at any time of year in tropical and subtropical areas, so long as certain Aedes species of mosquitoes are present and active. Zika virus is thought to affect all age groups in both sexes. Clinically, only one in five of those infected with Zika virus is thought to become symptomatic, usually with a febrile illness commonly associated with rash, polyarthralgia, and/or conjunctivitis (CDC Zika virus website). Recently, preliminary reports suggest Zika virus infection may be associated with Guillain-Barré syndrome, microcephaly, and ophthalmologic birth defects, and these associations are currently under investigation (CDC Zika virus website; European Centre for Disease Prevention and Control 2015; Martines et al. 2016; Gatherer and Kohl 2015; Oehler et al. 2014; Ventura et al. 2016). Diagnosis of Zika virus infection can be challenging given antibody cross-reactivity among the flaviviruses, including the dengue viruses, though PRNTs may be able to differentiate among primary flavivirus infections. Molecular testing with RT-PCR is arguably the most useful test for confirmation at this time, but this requires relatively acute samples (CDC Zika virus website). Currently, only the CDC Arbovirus Diagnostic Laboratory and a few state public health laboratories are able to test for Zika virus infection in North America, though other public health laboratories may be able to test for it in the future. Given the rapidly evolving nature of the current Zika virus disease epidemic, the most up-to-date information and recommendations can be found on the CDC Zika virus website (CDC Zika virus website).

Given the increased recognition of Jamestown Canyon virus and Powassan virus, and the emergence of chikungunya virus and Zika virus in North America, clinicians should be aware of their potential resultant illnesses. Any suspected cases of Jamestown Canyon, Powassan, chikungunya, or Zika virus disease should be reported to local and/or state public health departments, who can often facilitate arboviral diagnostic testing. Unfortunately, there are currently no proven disease-modifying therapies for these arboviral diseases, so treatment is largely supportive. Given there are also no commercially available vaccines for these four arboviral infections, prevention is key. To prevent mosquito or tick bites that might result in one of these arboviral diseases, people should wear long-sleeved shirts and pants while outside if feasible, apply insect repellant when going outdoors, using window screens or air conditioning to keep mosquitoes outside, and perform tick checks after being in wooded or brushy outdoor areas (CDC Prevent Mosquito Bites Website; CDC Preventing Tick Bites website).

\section{Compliance with ethical standards}

Conflict of interest The authors declare that they have no conflict of interest.

\section{References}

Aguirre AA, McLean RG, Cook RS, Quan TJ (1992) Serologic survey for selected arboviruses and other potential pathogens in wildlife from Mexico. J Wildl Dis 28(3):435-442

Anderson JF, Main AJ, Armstrong PM, Andreadis TG, Ferrandino FJ (2015) Arboviruses in North Dakota, 2003-2006. Am J Trop Med Hyg 92(2):377-393

Andreadis TG, Anderson JF, Armstrong PM, Main AJ (2008) Isolations of Jamestown Canyon virus (Bunyaviridae: Orthobunyavirus) from fieldcollected mosquitoes (Diptera: Culicidae) in Connecticut, USA: a tenyear analysis, 1997-2006. Vector Borne Zoonotic Dis 8(2):175-188

Angelini R, Finarelli AC, Angelini P et al (2007) An outbreak of chikungunya fever in the province of Ravenna, Italy. Euro Surveill 12(9):E070906.070901

CDC "Arbocat" Website. Available via: https://wwwn.cdc.gov/arbocat/. Accessed January 5, 2016.

CDC “Chikungunya Virus" Website. Available via: http://www.cdc.gov/ chikungunya/. Accessed January 5, 2016.

CDC "Powassan Virus" Website. Available via: http://www.cdc.gov/ powassan/. Accessed January 5, 2016.

CDC "Prevent Mosquito Bites" Website. Available via: http://www.cdc. gov/features/stopmosquitoes/. Accessed January 5, 2016.

CDC "Preventing Tick Bites" Website. Available via: http://www.cdc. gov/ticks/avoid/on_people.html. Accessed January 5, 2016.

CDC “Zika Virus” Website. Available via: http://www.cdc.gov/zika/. Accessed January 5, 2016.

Deibel R, Srihongse S, Grayson MA et al (1983) Jamestown Canyon virus: the etiologic agent of an emerging human disease? Prog Clin Biol Res 123:313-325

Duffy MR, Chen TH, Hancock WT et al (2009) Zika virus outbreak on Yap Island, Federated States of Micronesia. N Engl J Med 360(24): 2536-2543

Ebel GD (2010) Update on Powassan virus: emergence of a North American tick-borne flavivirus. Annu Rev Entomol 55:95-110

European Centre for Disease Prevention and Control (2015) Rapid risk assessment: Zika virus epidemic in the Americas: potential association with microcephaly and Guillain-Barré syndrome-10 December 2015. ECDC, Stockholm, Available via: http://ecdc.europa.eu/en/ publications/Publications/zika-virus-americas-association-withmicrocephaly-rapid-risk-assessment.pdf/. Accessed January 5, 2016

Fischer M, Staples JE (2014) Notes from the field: chikungunya virus spreads in the Americas - Caribbean and South America, 20132014. MMWR Morb Mortal Wkly Rep 63(22):500-501

Gatherer D, Kohl A (2015) Zika virus: a previously slow pandemic spreads rapidly through the Americas. J Gen Virol

Gerardin P, Couderc T, Bintner M et al (2016) Chikungunya virusassociated encephalitis: a cohort study on La Reunion Island, 2005-2009. Neurology 86(1):94-102

Grimstad PR, Calisher CH, Harroff RN, Wentworth BB (1986) Jamestown Canyon virus (California serogroup) is the etiologic agent of widespread infection in Michigan humans. Am J Trop Med Hyg 35(2):376-386

Hinten SR, Beckett GA, Gensheimer KF et al (2008) Increased recognition of Powassan encephalitis in the United States, 1999-2005. Vector Borne Zoonotic Dis 8(6):733-740 
Johnson DK, Staples JE, Sotir MJ, Warshauer DM, Davis JP (2010) Tickborne Powassan virus infections among Wisconsin residents. WMJ 109(2):91-97

Lebrun G, Chadda K, Reboux AH, Martinet O, Gauzere BA (2009) Guillain-Barre syndrome after chikungunya infection. Emerg Infect Dis 15(3):495-496

Martines RB, Bhatnagar J, Keating MK, Silva-Flannery L, Muehlenbachs A, Gary J, Goldsmith C, Hale G, Ritter J, Rollin D, Shieh WJ, Luz KG, Ramos AM, Davi HP, Kleber de Oliveria W, Lanciotti R, Lambert A, Zaki S (2016) Notes from the field: Evidence of Zika virus infection in brain and placental tissues from two congenitally infected newborns and two fetal losses - Brazil, 2015. MMWR Morb Mortal Wkly Rep 65(06):1-2

Musso D, Nilles EJ, Cao-Lormeau VM (2014) Rapid spread of emerging Zika virus in the Pacific area. Clin Microbiol Infect 20(10):O595O596

Oehler E, Watrin L, Larre P, et al. Zika virus infection complicated by Guillain-Barre syndrome-case report, French Polynesia, December 2013. Euro Surveill. 2014;19(9).
Oehler E, Fournier E, Leparc-Goffart I, et al (2015) Increase in cases of Guillain-Barre syndrome during a Chikungunya outbreak, French Polynesia, 2014 to 2015. Euro Surveill.;20(48). doi: 10.2807/15607917.ES.2015.20.48.30079.

Pastula DM, Hoang Johnson DK, White JL, Dupuis AP 2nd, Fischer M, Staples JE (2015) Jamestown Canyon virus disease in the United States - 2000-2013. Am J Trop Med Hyg 93(2):384-389

Staples JE, Breiman RF, Powers AM (2009) Chikungunya fever: an epidemiological review of a re-emerging infectious disease. Clin Infect Dis 49(6): $942-948$

Thiberville SD, Moyen N, Dupuis-Maguiraga L et al (2013) Chikungunya fever: epidemiology, clinical syndrome, pathogenesis and therapy. Antiviral Res 99(3):345-370

Ventura CV, Maia M, Ventura BV, Linden VV, Araújo EB, Ramos RC, Rocha MA, Carvalho MD, Belfort R Jr, Ventura LO (2016) Ophthalmological findings in infants with microcephaly and presumable intra-uterus Zika virus infection. Arq Bras Oftalmol 79(1):1-3

Walters LL, Tirrell SJ, Shope RE (1999) Seroepidemiology of California and Bunyamwera serogroup (Bunyaviridae) virus infections in native populations of Alaska. Am J Trop Med Hyg 60(5):806-821 